\title{
The Bruce effect revisited: is pregnancy termination in female rodents an adaptation to ensure breeding success after male turnover in low densities?
}

\author{
Jana A. Eccard ${ }^{1,2}\left(\mathbb{0} \cdot\right.$ Melanie Dammhahn ${ }^{1} \cdot$ Hannu Ylönen $^{2,3}$
}

Received: 8 February 2017 / Accepted: 20 June 2017 / Published online: 9 August 2017

(C) The Author(s) 2017. This article is an open access publication

\begin{abstract}
Pregnancy termination after encountering a strange male, the Bruce effect, is regarded as a counterstrategy of female mammals towards anticipated infanticide. While confirmed in caged rodent pairs, no verification for the Bruce effect existed from experimental field populations of small rodents. We suggest that the effect may be adaptive for breeding rodent females only under specific conditions related to populations with cyclically fluctuating densities. We investigated the occurrence of delay in birth date after experimental turnover of the breeding male under different population composition in bank voles (Myodes glareolus) in large outdoor enclosures: one-male-multiple-females ( $n=6$ populations/18 females), multiple-males-multiplefemales $(n=15 / 45)$, and single-male-single-female (MF treatment, $n=74 / 74)$. Most delays were observed in the MF treatment after turnover. Parallel we showed in a laboratory experiment ( $n=205$ females) that overwintered and primiparous females, the most abundant cohort during population lows in the increase phase of cyclic rodent populations, were more likely to delay births after turnover of the male
\end{abstract}

Communicated by Roland A. Brandl.

Electronic supplementary material The online version of this article (doi:10.1007/s00442-017-3904-6) contains supplementary material, which is available to authorized users.

Jana A. Eccard

eccard@uni-potsdam.de

1 Animal Ecology, University of Potsdam, Maulbeerallee 1, 14469 Potsdam, Germany

2 Biological and Environmental Sciences, University of Jyväskylä, Jyväskylä, Finland

3 Konnevesi Research Station, University of Jyväskylä, Jyväskylä, Finland than year-born and multiparous females. Taken together, our results suggest that the Bruce effect may be an adaptive breeding strategy for rodent females in cyclic populations specifically at low densities in the increase phase, when isolated, overwintered animals associate in MF pairs. During population lows infanticide risk and inbreeding risk may then be higher than during population highs, while also the fitness value of a litter in an increasing population is higher. Therefore, the Bruce effect may be adaptive for females during annual population lows in the increase phases, even at the costs of delaying reproduction.

Keywords Breeding strategies - Dip test - Infanticide · Myodes voles $\cdot$ Sexual conflict $\cdot$ Sexual selection

\section{Introduction}

Sexual conflict is prevailing in most sexually reproducing species due to sexual dimorphism in gamete size, costs involved in mating and differential parental investment. Infanticide by non-parental males is a prominent example of the evolutionary conflict between the reproductive interests of males and females (Parker 1979, 2006) with females loosing reproductive investment, while males increase their chance of mating with the female. In mammals, infanticide has primarily evolved in group-living species, where reproduction is monopolised by a few dominant males (Lukas and Huchard 2014), and the care for dependent young prevents or delays females to engage in a subsequent reproductive attempt until current offspring are independent. Infanticide by non-parental males may, thus, have evolved to increase the infanticidal male's chances to reproduce with the female by shortening the inter-birth interval (Hrdy 1979). 
In turn, females evolved several counterstrategies to male infanticide (summarised in Lukas and Huchard 2014), including promiscuity to confuse paternity, direct attack of potential perpetrators (Ylönen and Horne 2002), avoidance of infanticidal individuals, territoriality, as well as early termination of pregnancy (reviewed in Ebensperger and Blumstein 2007), the latter can also be called the 'anticipated infanticide avoidance hypothesis'. This cessation of pregnancy at early stages is known as pregnancy block or the Bruce effect (Bruce 1959, 1960; Milligan 1976) and might reduce the energetic investment into young that are under threat to be killed by an invading male (Hrdy 1979; Schwagmeyer 1979; Ebensperger 1998; Roberts et al. 2012). Delayed pregnancies after take-over of one-male groups by a new male are often considered as an indicator of the Bruce effect, and were observed in free-ranging primates (Theropithecus gelada: Roberts et al. 2012), rodents (Marmota marmota: Hackländer and Arnold 1999), and odd-toed ungulates (Equus caballus, Berger 1983). Female mice (Mus musculus) might block pregnancies before implantation (Bruce 1959), but many other mammals disrupt pregnancies at later stages (voles: Stehn and Jannett 1981; Heske and Nelson 1984; Heske 1987, rats: Marashi 2012). Although early and late pregnancy terminations may be caused by different physiological mechanisms, they are often also subsumed under a broader Bruce or Bruce-like effect; we follow this classification. Further adaptive explanations for the Bruce effect include pregnancy blocking if it increases genetic compatibility (Yamazaki et al. 1983, but see Rülicke et al. 2006).

Hitherto evidence for the Bruce effect in small rodents comes from captive conditions (e.g., house mice: Bruce 1959; Parkes and Bruce 1961; Yamazaki et al. 1983; Rülicke et al. 2006; voles: reviewed in Stehn and Jannett 1981; vole pairs in very small $\left(<4 \mathrm{~m}^{2}\right)$ enclosures: Heske and Nelson 1984; Heske 1987, Norway rats: Marashi 2012). Mainly due to the lack of conclusive field evidence, the adaptive value of this potential female counterstrategy to male infanticide remains elusive in small rodents (Heske and Nelson 1984). In wild populations, females often show ovulation scars in spring, similar to those from experimentally induced pregnancy interruptions (Mallory and Clulow 1977), but these scars may as well be a consequence of sterile matings, triggering or 'priming' reproduction (Westlin 1981).

Evidence from experimental population studies on small rodents is also ambiguous. In such studies, large grassland enclosures were stocked with mixed-sex vole populations in high to very high densities. Populations that underwent an experimental replacement of males were compared to socially stable controls. As a result, timing of the first litter was delayed in some females after turnover of males (Microtus canicaudus: de la Maza et al. 1999, Microtus ochrogaster: Mahady and Wolff 2002), a second litter was delayed (Microtus oeconomus: Andreassen and Gundersen 2006), or recruitment of offspring was delayed (Mahady and Wolff 2002; Andreassen and Gundersen 2006; Opperbeck et al. 2012). Using mean values of reproductive timing per population, infanticide and pregnancy termination could not be disentangled and the use of population mean values potentially blurred information on females' individual decisions. Although the results were somehow similar among all studies, they were interpreted as either "no support" (de la Maza et al. 1999), "very little support" (Mahady and Wolff 2002), an "indication" for the occurrence of a Bruce effect (Andreassen and Gundersen 2006), or the Bruce effect was not considered in the interpretation of results (Opperbeck et al. 2012). Hence, field evidence for the occurrence of pregnancy termination as a potential female counterstrategy to male turnover in small rodent populations is equivocal. Some authors have, therefore, considered the Bruce effect in rodents a laboratory artefact (Wolff 2003), where a caged female cannot avoid the male. Here, we suggest that the captive conditions producing a Bruce effect in small rodents have not yet been compared to analogous field conditions, and that the Bruce effect may be adaptive and common in nature in fluctuating rodent populations, however, only under a limited range of social and reproductive conditions, which we aim to identify in this study.

In many rodent species, populations undergo annual density fluctuations associated with changes in age structure as well as fundamental aspects of the social and breeding system. For example, in striped mice (Rhabdomys pumilio), females breed solitarily in low density or in one-male groups in high density (Schradin and Pillay 2005). Similarly, prairie voles ( $M$. ochrogaster) breed monogamously at low density, but polygynandrously at high density (Lucia et al. 2008; Streatfeild et al. 2011). Thus, considering variation in population density, sex ratio, or breeding system as aspects of the social environment appears to be crucial to assess the adaptive value of pregnancy termination. We suggest that the Bruce effect in rodents may be an adaptation in fluctuating populations to breeding in single-female-single-male breeding units at low densities in the increase phase, and to the associated high risk of inbreeding or infanticide. With spring litters having a high reproductive value in increasing seasonal populations, preventing infanticide or inbreeding by pregnancy termination may be highly adaptive for a rodent female in the increase phase of the cycle, even at the costs of delaying her reproduction.

We studied if a delay in birth date, likely due to the Bruce effect occurred in rodent populations under seminatural conditions in different social environments, using bank voles (Myodes glareolus) as the study system. Bank voles have a polygynandrous breeding system when possible (Klemme et al. 2007, 2008) and show infanticidal behaviour of males (Ylönen and Horne 2002). Bank vole 
populations show annual density fluctuations with lows during winter and spring, and small social aggregations as well as large breeding groups were observed in the wild (Ylönen et al. 1988; Ylönen and Viitala 1991). Population highs build up during summer and start to decline in autumn and reach the lowest densities during subsequent spring (Fig. 1). They also show multiannual density fluctuation in part of their range (Yoccoz et al. 2001; Crespin et al. 2002) and during the population low or crash the densities reach very low values, which we expect to affect the breeding strategy of surviving individuals. Many small rodent genera have very similar population characteristics. The Bruce effect was shown in captivity (Mus: Bruce 1959, 1960; Milligan 1976; Microtus: e.g. Mallory and Clulow 1977; Stehn and Jannett 1981), we, therefore, assumed that bank voles were suitable for our study. To confirm that bank voles are able to delay births, and to confirm that the time interval of male turn-over chosen for our semi-natural study could potentially produce a delay of births, we conducted a side study on captive bank vole pairs which is also presented in this article.

In a series of experiments in semi-natural, large grassland enclosures we investigated the effect of social environment on the delay of birth dates. We created different social population structures differing pronouncedly in the number of possible mating partners. In each experiment, we compared the timing of births in stable population where we did not expect the Bruce effect, with the timing of birth in populations with turnover of males, where the Bruce effect can be expected. Populations consisted either of a single female with a single male (MF), multiple females with a single male (MFFF), or multiple females with several males (MMMFFF). We predicted,
1. If pregnancy termination after male turnover is adaptive only for a female breeding in pair constellation, i.e., with one male in a low density phase, but not for promiscuously or harem breeding females in higher densities, a delay in birth date should be more common in the MF experiment than in any of the group experiments [rate of late births (MF > (MFFF and MMMFFF)]. As discussed above, earlier studies on the Bruce effect in experimental populations were always conducted in multi-male-multi-female populations (de la Maza et al. 1999; Mahady and Wolff 2002; Andreassen and Gundersen 2006; Opperbeck et al. 2012), which may explain equivocal results.

2. As an alternative hypothesis, pregnancy termination may be an alternative strategy to paternity confusion avoiding infanticide or inbreeding. If so, delay in birth dates should be more common in the single-male populations without additional males to mate with, than in a multimale population. Many rodents breed promiscuitively (Eccard and Wolf 2009; Klemme et al. 2007). To test this hypothesis, we compared multi-female populations and expected a higher rate of late births in single-male versus multi-male conditions (MFFF $>$ MMMFFF). In Southern African vlei rats (Otomys irroratus) originating from "polygynous populations" females had higher rates of pregnancy termination in caged pair conditions than females from "promiscuous populations" (Pillay and Kinahan 2009), supporting our hypothesis.

3. If absolute animal density affects the Bruce effect (as proposed in the lab artefact discussion, Wolff 2003), delayed births should be more common at higher compared to lower densities (MMMFFF $>$ MFFF $>M F$ ) in same sized enclosures. Moreover, for MF experiments, late births should be more common in smaller (higher
Fig. 1 Counter-strategies of female rodents to infanticide risk or inbreeding risk adapted to the annual population density cycle and population structure $(O W$ : overwintered, $Y Y$ : yearborn, for maturation and reproduction of age classes see also Eccard and Herde 2013). In very low spring densities rodents may breed in pairs but change to polygynandrous breeding in high summer densities. Selection pressure on breeding behaviour may be highest during population bottlenecks in spring because of high fitness value of spring litters in increasing populations

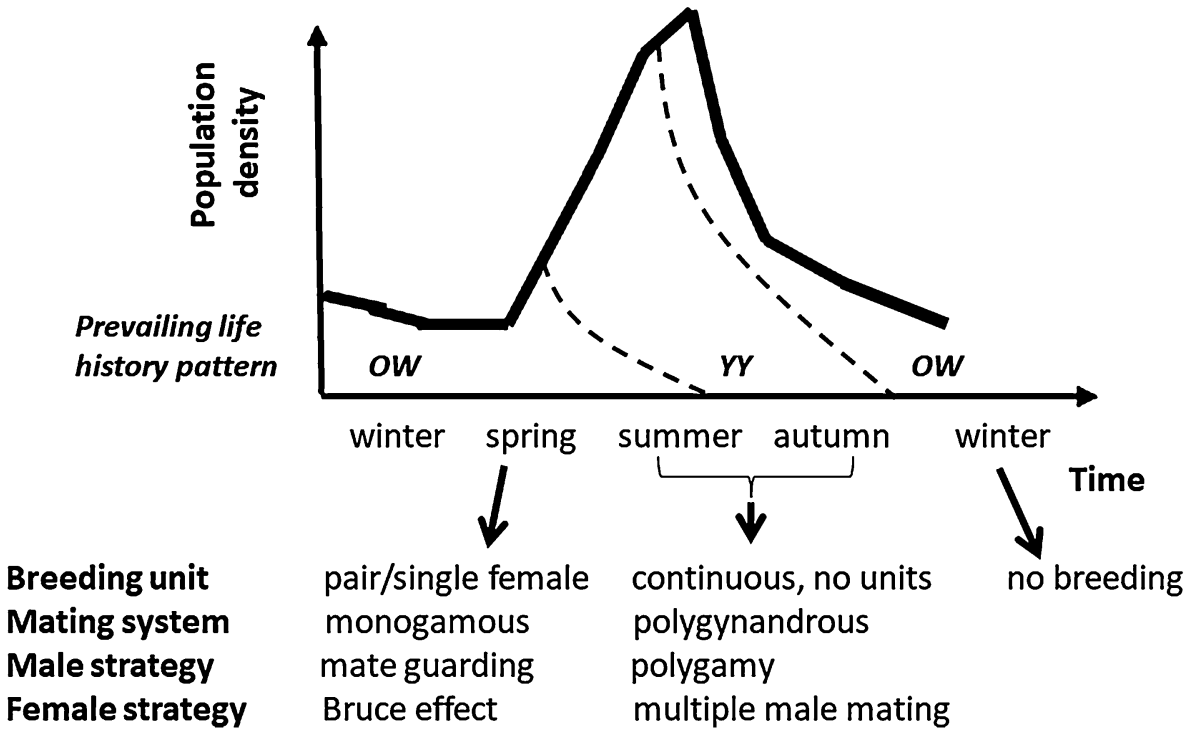


density) than in larger (lower density) enclosures (MF smaller $>$ MF larger enclosures).

To investigate the evolutionary significance of the Bruce effect in annual population structure and dynamic, we compared rates of delayed births in different age cohorts of females in the aforementioned parallel study in captive bank voles and in some of the multi-female populations. In natural populations, annual density fluctuations go along with changes of demographic structure (Eccard and Herde 2013). Low densities occur annually in spring (Fig. 1), when the majority of individuals are overwintered $(\mathrm{OW})$ and first time breeders (nulliparous (n), here referred to OW-n). The first generation of offspring born in the same year (young of year, YY), breeds for the first time (YY-n) at an intermediate density, depending on the number of founder females. Later in the breeding season, all breeders are experienced, established breeders [parous (p)] and can be of both age cohorts (OW-p and YY-p). Towards the end of the year, densities are high and breeding territories occupied, than young YY females cannot enter the breeding population and their maturation is suppressed (Prevot-Julliard et al. 1999). Accordingly, if the Bruce effect is adaptive in low population densities, we expected higher rates of delayed births in the cohorts most common during population lows.

4. Specifically, we predict higher rates of late births in overwintered, first time breeders compared to yearborne, experienced breeders [OW-n $>$ (YY-p and OW-p)]. The combination YY-n, which occurs at intermediate densities, may be intermediate also in the rate of delayed births. There are indications that females of different cohorts are differentially likely to show the Bruce effect: first time breeders more likely interrupted a pregnancy than experienced breeders (Stehn and Jannett 1981; Clulow et al. 1982, but see Chipman and Fox 1966); and younger females more likely than older females (Clulow and Langford 1971; Heske 1987).

Combining both laboratory and field data, we aimed to identify social environmental and demographic conditions under which the Bruce effect occurs, and relate these to natural fluctuations of population density and demography to understand whether and when the Bruce effect could be an adaptive breeding strategy for female rodents in low density populations in the population increase phase (Fig. 1).

\section{Materials and methods}

The study was conducted on colony-bred bank vole females (M. glareolus) and encompasses four experiments. In
1999-2001 in Konnevesi, Central Finland, we conducted two field experiments in multi-female groups with different number of males. In 2014-2015, we conducted a third field experiment near Potsdam, Eastern Germany, on populations of a single breeding pair. Enclosure sizes, colony origin of voles, time schedules and turnover treatments of the experiments were corresponding (Table 1). Experiments differed in location, year, marking method of voles and composition of populations. The fourth part of the study was a breeding experiment on captive voles conducted in Konnevesi in 1999-2000, where we used the same turnover treatments and breeding schedules as in all field experiments. Voles at both facilities were bred in standard mouse cages at $18-22^{\circ} \mathrm{C}$ and fed on lab chow with water ad libitum. Voles were kept at 14-16-h daylight during summer breeding season and 8-h daylight during non-breeding season in winter. Experiments were integrated into breeding routines of voles in colony and enclosures.

\section{Study species and experimental animals}

Bank vole females were offspring (F1 or F2) of wild caught animals and were either first time breeders (nulliparous, $\mathrm{n}$ ) or experienced breeders (parous, $\mathrm{p}$ ). They were either born in the previous autumn (OW) or the same season (YY). Nulliparous, overwintered females (OW-n) had an age of 5-7 months and a body mass of 18-25 g. Nulliparous YY females (YY-n) were 1-2 months old and weighed 10-15 g at the start of the experiment. Parous OW (OW-p) and YY females (YY-p) were 7-12 and 5-8 months old, respectively, and weighed between 18 and $30 \mathrm{~g}$. Males were 5-12 months old and had a body mass of 18-30 g. Males were captured directly from the wild or had been experienced and successful breeders in the laboratory. Sample sizes of the female cohorts are given under the respective experiments.

The schedule of male turnover treatments was the same for all experiments, both experimental populations and captive pairs. Male turnover was conducted in weekly intervals and births were recorded as experimental days. After release to the enclosure/breeding cage (experimental day 1) voles were kept together for seven days. On experimental day 7 , original males were removed and either returned to the enclosure/breeding cage (returned male treatment) or replaced by different individuals (replaced male treatment). Animals were kept together for another 7 days (experimental days 7-14). After removal from enclosure/breeding cage at day 14 , females were kept in separate cages and inspected daily to document occurrence of pregnancy and birth dates. With a bank vole pregnancy lasting $20 \pm 2$ (mean \pm SD) days (Bujalska 1983), we assumed that litters born early during experimental days 18-25 were conceived during days 1-7. Litters born late during experimental days 26-34 were 
Table 1 Experimental population experiments on pregnancy termination in bank voles in large outdoor enclosures with different population compositions: multi-male-multi-female (MMMFFF), single-malemulti-female (MFFF), and an isolated breeding pair (MF), where each M (and each $F$ ) resembles one male (one female, respectively) per population

\begin{tabular}{|c|c|c|c|c|c|c|}
\hline & \multicolumn{6}{|c|}{ Composition of population } \\
\hline & \multicolumn{2}{|c|}{ MMMFFF } & \multicolumn{2}{|l|}{ MFFF } & \multicolumn{2}{|l|}{ MF } \\
\hline Location & \multicolumn{2}{|l|}{ Finland } & \multicolumn{2}{|l|}{ Finland } & \multicolumn{2}{|l|}{ Germany } \\
\hline Year & \multicolumn{2}{|l|}{1999} & \multicolumn{2}{|l|}{$1999+2000$} & \multicolumn{2}{|l|}{$2014+2015$} \\
\hline Enclosure size large/small $\left[\mathrm{m}^{2}\right]$ & \multicolumn{2}{|l|}{ 2500/- } & \multicolumn{2}{|l|}{$2500 /-$} & \multicolumn{2}{|l|}{$2500 / 255$} \\
\hline Vole density [ind./ha] large/small & \multicolumn{2}{|l|}{$24 /-$} & \multicolumn{2}{|l|}{$16 /-$} & \multicolumn{2}{|l|}{$8 / 88$} \\
\hline \multicolumn{7}{|l|}{ Females } \\
\hline $\begin{array}{l}\text { Overwintered, nulliparous } \\
\text { (OW-n) }\end{array}$ & \multicolumn{2}{|l|}{2} & \multicolumn{2}{|l|}{12} & \multicolumn{2}{|l|}{-} \\
\hline Overwintered, parous (OW-p) & \multicolumn{2}{|l|}{6} & \multicolumn{2}{|l|}{6} & \multicolumn{2}{|l|}{-} \\
\hline Yearborn, nulliparous (YY-n) & \multicolumn{2}{|l|}{4} & \multicolumn{2}{|l|}{25} & \multicolumn{2}{|l|}{74} \\
\hline Yearborn, parous (YY-n) & \multicolumn{2}{|l|}{6} & \multicolumn{2}{|l|}{2} & \multicolumn{2}{|l|}{-} \\
\hline \multicolumn{7}{|l|}{ Sample sizes } \\
\hline Turnover treatment & Replace & Return & Replace & Return & Replace & Return \\
\hline No. of experimental populations & 3 & 3 & 10 & 5 & 38 & 36 \\
\hline No. of recaptured females & 8 & 9 & 23 & 14 & 27 & 18 \\
\hline No. of births of litters & 8 & 7 & 17 & 12 & 21 & 14 \\
\hline $\begin{array}{l}\text { No. of births with complete } \\
\text { retrieval of experimental males } \\
\text { from field }\end{array}$ & 8 & 7 & 17 & 12 & 11 & 10 \\
\hline $\begin{array}{l}\text { No. of births from nulliparous } \\
\text { mothers with complete retrieval }\end{array}$ & 3 & 1 & 14 & 10 & 11 & 10 \\
\hline
\end{tabular}

After 1 week original males were removed and either replaced by a different male or returned (turnover treatments). Population replicates were conducted in rounds with simultaneous returned and replaced treatments. Original data are available in the data ESM appendix conceived during days $7-14$ and could be sired either by the returned original male or the replacement male, depending on turnover treatment.

\section{Three field experiments: replacement of male(s) in different population compositions}

We investigated the occurrence of delayed births in three experiments with two parallel male turnover treatments within each experiment. Experiments corresponded in the species used, habitat type in enclosures, size of enclosures, type and number of traps, trap control intervals, and schedule of male turnover (Table 1). Experimental populations were kept in large $(50 \mathrm{~m} \times 50 \mathrm{~m})$ grassland enclosures or, in the MF experiment, we additionally included a set of smaller $(15 \mathrm{~m} \times 15 \mathrm{~m})$ enclosures, (Table 1). Enclosures had a permanent trapping grid of Ugglan multiple capture life traps (Grahn AB, Sweden).

Experiments differed by their population composition: (1) single-male-single-female population (MF) with one male and one female per enclosure $(n=74$ populations, 74 females), (2) single-male-multiple-female populations (MFFF) with one male and three females per enclosure ( $n=14$ populations, 42 females), (3) multi-male-multifemale populations (MMMFFF) with thee males and three females per enclosure ( $n=6$ populations, 18 females).
Experiments also differed by the combination of female age and reproductive history, location, animal marking method and years (Table 1). Within each experiment, we conducted several simultaneous replicates of the returned male and replaced male treatments.

In the multi-female experiments, we released three females per population to an enclosure, which allows all of them to breed (Eccard et al. 2011). According to seasonal availability of different cohorts (Fig. 1), experimental populations consisted of females of different ages or reproductive history (Table 1), always distributed equally across the populations.

Voles were individually marked and released to the centre of the enclosure on experimental day 1. Livetrapping was conducted after 1 week for one night, after which females were returned to the original enclosure, while males were either replaced with different individuals or returned. In total, we released 137 vole females to the enclosures and recaptured 99 females of which 79 were gravid. After excluding those replicates where recapture of males was incomplete, we analysed the timing of birth for 65 gravid females (Table 1). We repeated analyses of timing of birth for a data set restricted to nulliparous females ( $n=49$ females, 4 MMMFFF, 24 MFFF, 21 MF) where we had to pool data of multi-female populations $(4+24=28$ females). 
Vole densities in the large enclosures (Table 1) corresponded to densities in the increasing phase, whereas densities in the small enclosure represented the peak phase of the population cycle (Ylönen et al. 1988; Eccard et al. 2011), allowing us to investigate the effect of population composition within large enclosures (among experiments) and of densities within MF experiments (between large and small enclosures)

Pairing experiment on captive bank voles: effects of female cohort and replacement of the pair male on timing of pregnancies (MF)

Pairings were conducted in spring 2000 as part of the breeding routine in the bank vole colony. Females of the replaced male treatment were transferred to a clean cage or the males' cage and paired to a different male during experimental days 7-14. Females of the returned male treatment were transferred to a clean cage and paired again to the original male during day 7-14. In total, we monitored pairings of 204 females of three different age and parity cohorts $(N=113$ OW-n females, $N=59$ YY-n females and $N=32$ YY-p females) with a male.

\section{Statistical analyses}

We obtained binary response variables of the occurrence of birth versus no birth; and of early versus late births, respectively. Assuming that the Bruce effect is restricted to specific compositions of the population, we expected interactive effects of male turnover treatment with population composition (field experiments) on the timing of births. Assuming that the Bruce effect is restricted to specific age cohorts of females, we expected interactive effects of male turnover treatment with female cohort (laboratory experiment) on the timing of births. We, therefore, modelled these interactive effects both on the probability of females giving birth, and the probability of late births in separate generalised linear models (GLMs) with binomial error distribution. If the statistical model indicated a marginal support $(p<0.1)$ for any of the specified interactions among two factors, we subsequently investigated simple effects of one factor within levels of the other factor using a $\mathrm{Chi}^{2}$-test, or in case of low sample size using Fisher's exact test, as post hoc tests for an association.

Since in previous experiments on the Bruce effect in other rodent species (e.g., Clulow et al. 1982) not all but a fraction of females terminated pregnancies after male replacement, we expected a bimodal distribution of birth dates for the replaced male treatments, including a first peak of early births around day 20 and a second peak of late births around day 27 . For the returned male treatment, we expected a unimodal distribution, peaking at early births around experimental day 20. To investigate modality in birth dates we used the Hartigans' Dip test for unimodality (Hartigan and Hartigan 1985) run with the R-package 'dip test' (Maechler 2013). This test detects deviations from unimodality (i.e., $p<0.05$ indicates non-unimodality). Upon detection of a deviation, we inspected the histograms of birth day (experimental day) frequencies and report the location of modes.

Nulliparous bank vole females in laboratory colonies not always conceived after being paired to a male, while once females started breeding they easily continue to breed (J.A.E. own observations). Hence, offering an additional male in the replaced male treatments may simply increase the chance of mating with a compatible partner. Since we were not able to distinguish between replaced pregnancies and additional pregnancies, we also analysed the pregnancy rate (i.e., the occurrence of pregnancy) from the experiments. We assumed that a combined increase of late pregnancy rate AND of overall pregnancy rates would indicate the occurrence of additional pregnancies, while an increase of late pregnancies without higher overall pregnancy rates would indicated a replacement of original pregnancies with the respective new male. A termination of pregnancy without a continuation of breeding, we assume to be highly unlikely, since once short lived rodent females get into breeding condition, they easily continue to breed.

The three females within an experimental MFFF or MMMFFF population may not be seen as completely independent samples, we, therefore, used generalised linear mixed model (GLMM) including population as a random factor (Zuur et al. 2009) in the analysis of multiple-female experiments (Hypothesis 2 and 4).

Statistical analyses were performed with $\mathrm{R} 3.1 .0$ (R-Development-Core-Team 2013) using R-studio (RStudio Team 2015) and R-commander (Rcmdr, Fox 2005), and the packages 'Ime4' (version 1.1-6, Bates et al. 2014) and 'car' (version 2.0-20, Fox and Weisberg 2011). Original data can be found in the online material (ESM Appendix 1).

\section{Results}

In the field experiments, 65 births were observed in 81 recaptured females ( $80 \%$ pregnancy rate). A total of 11 litters (17\% of the births) were born late. In the full model, there was a tendency for an interaction effect of population composition with male turnover treatment on the probability of late births (turnover treatment: $X^{2}=0.0, d f=1$, $p=0.93$, composition: $X^{2}=6.2, d f=2, p=0.045$, interaction $X^{2}=4.8, p=0.093$, Fig. 2, Table 2, for post hoc tests see respective $\mathrm{H} 1$ and $\mathrm{H} 2$ below).

In the experiment on captive pairs a total of 146 litters were born to 204 females (72\% pregnancy proportion), of 
which $26 \%$ (38) were born late. Both male turnover treatment and cohort explained late litters rates, without interaction (turnover treatment: $X^{2}=7.1, d f=1, p=0.008$, cohort: $X^{2}=10.1, d f=2, p=0.008$, interaction: $X^{2}=1.0, p=0.56$, Fig. 2; Table 2, discussed at respective hypotheses $\mathrm{H} 1$ and H4 below).

\section{H1: The Bruce effect in single-male-single-female breeders [proportion of late litters: MF > MFFF and MF > MMMFFF)]}

After a turnover of the breeding male, females in MF conditions had a higher proportion of late litters compared to females in multi-female conditions (simple-effect tests within treatment levels: within the replaced male treatment, the proportion of late litters was associated to population composition (Table 3): MF females produced a higher proportion of late litters $(45 \%, 5$ out of 11$)$ than MFFF females $(6 \%, 1 / 17$, Fishers exact: $p=0.018)$ and tended to produce a higher proportion of late litters than MMMFFF females $(0 \%, 0 / 7, p=0.10)$. MFFF and MMMFFF females did not differ in the proportion of late litters ( 6 and $0 \%, p=1.00)$. In the data set restricted to nulliparous females these results were confirmed: after male replacement the proportion of late litters in MF females $(45 \%, 5 / 11)$ was higher than from (MFFF + MMMFFF) females $(6 \%, 2 / 28, p=0.018$; all other within-factor comparisons $p>0.36$ ). Dip tests indicated non-unimodal distribution of births in replaced male treatments (Fig. 3a, c), but while there were two modes (early births and late births) in the MF treatment (3c), there were two distinct modes of early births in the group treatments.

Within the returned male treatment in the full data set the proportion of late births $(19 \%, 5 / 29)$ was not associated to population composition $(p=0.58)$. Within none of the population compositions, the proportion of late litters was associated with male turnover treatments (returned and replaced treatments in MF pairs: 20 and 45\%, in MFFF: 8 and 6\%, in MMMFFF: 0 and 29\%, respective absolute numbers in Table 2, all $p>0.36$ ). Dip tests in the returned treatment (Fig. 3b, d) did not support other than one (early birth) mode.

In the experiment on captive pairs, male replacement resulted in a higher probability of late births (30 late out
Fig. 2 Laboratory and field experiments on conception and pregnancy termination (Bruce effect) in bank voles (Myodes glareolus) after turnover of breeding males (breeding male replaced, or returned (control) after capture). a Different population composition of males (M) and females $(\mathrm{F})$ in separate large outdoor enclosures $[n=84$ females, multi-male-multifemale (MMMFFF), singlemale-multi-female (MFFF), or isolated male-female (MF)]. b Laboratory experiment with caged male-female pairs $(n=204)$, females differed by age $(O W$ overwintered, $Y Y$ yearborn) and reproductive history ( $-n$ nulliparous, without birth prior to the first pairing, $-p$ parous: had reproduced before the trial)

\section{(a) Experimental populations male(s) male(s) returned replaced}
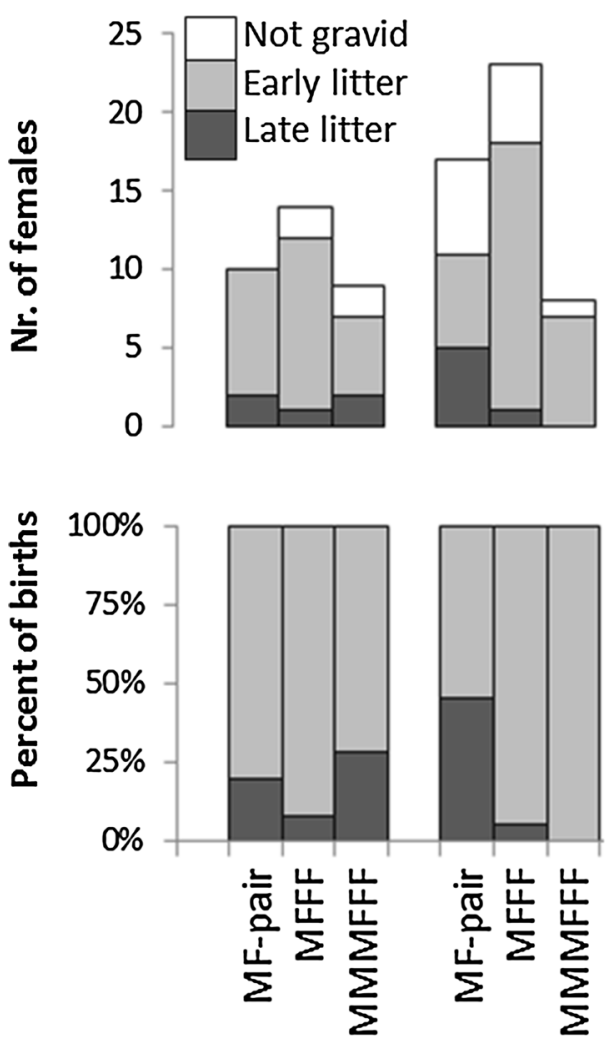

Composition of population

\section{(b) Captive pairs male male returned replaced}
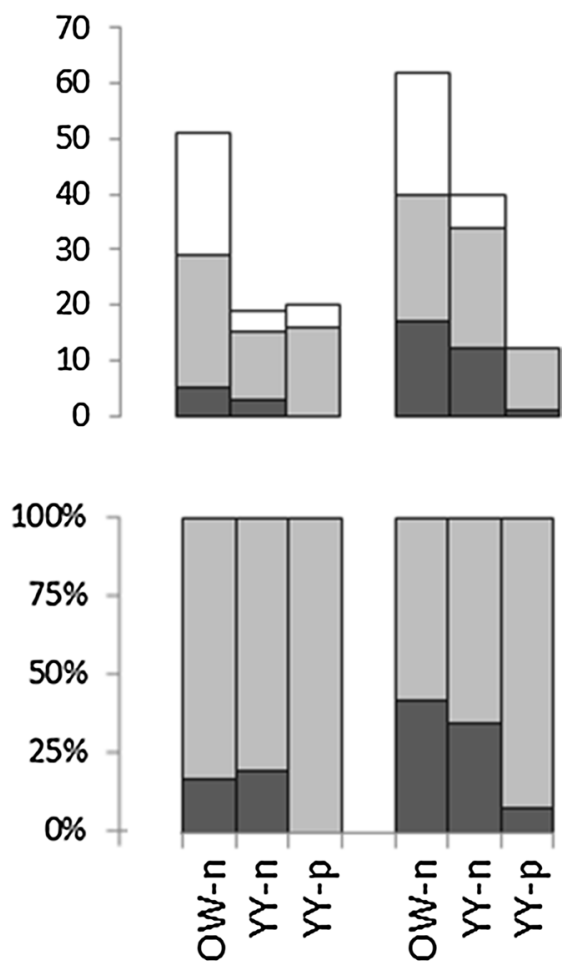
Table 2 Eccard et al. Oecologia, Bruce effect

\begin{tabular}{|c|c|c|c|c|c|}
\hline $\begin{array}{l}\text { Hypothesis, data base (sample size: early/ } \\
\text { late births, Model type) }\end{array}$ & Explanatory variable & Estimate & SE of estimate & $Z$ value & $p$ \\
\hline \multirow{4}{*}{$\begin{array}{l}\text { H1: Pair vs multiple breeders, population } \\
\text { experiments }(n=57 / 11, \text { GLM })\end{array}$} & (Intercept) & 1.7 & 0.6 & 2.7 & 0.008 \\
\hline & Turnover & 1.5 & 1.2 & 1.3 & 0.210 \\
\hline & Population composition & 0.3 & 1.0 & 0.3 & 0.776 \\
\hline & Interaction & 2.2 & 1.6 & 1.7 & 0.082 \\
\hline \multirow{5}{*}{$\begin{array}{l}\text { H4: Cohort effects, caged pairs }(n=138 / 38 \text {, } \\
\text { GLM) }\end{array}$} & (Intercept) & 1.5 & 0.4 & 3.6 & $<0.001$ \\
\hline & Turnover & 1.1 & 0.5 & 2.5 & 0.011 \\
\hline & YY-n:OW-n & 0.1 & 0.4 & 0.5 & 0.652 \\
\hline & YY-p:OW-n & 2.5 & 1.1 & 2.3 & 0.020 \\
\hline & YY-p:YY-n & 2.3 & 1.1 & 1.1 & $\mathbf{0 . 0 3 5}$ \\
\hline \multirow{4}{*}{$\begin{array}{l}\text { H2: Single vs multiple male, population } \\
\text { experiments female groups }(n=40 / 4 \text {, } \\
\text { GLMM) }\end{array}$} & (Intercept) & 0.4 & 0.7 & 2.1 & 0.031 \\
\hline & Turnover & 0.7 & 0.8 & 0.9 & 0.346 \\
\hline & No. of males & 0.1 & 1.0 & 0.1 & 0.897 \\
\hline & Interaction & 0.7 & 1.4 & 0.5 & 0.621 \\
\hline \multirow{4}{*}{$\begin{array}{l}\text { H4: Cohort effects, population experiments } \\
\text { female groups }(n=40 / 4, \text { GLMM })\end{array}$} & (Intercept) & 9.9 & 10.0 & 1.0 & 0.327 \\
\hline & Turnover & 2.1 & 9.3 & 0.1 & 0.920 \\
\hline & Age of females (OW:YY) & 2.5 & 7.6 & 0.3 & 0.739 \\
\hline & Reproductive history of females (n:p) & 4.1 & 7.1 & 0.6 & 0.563 \\
\hline
\end{tabular}

After 1 week original males were removed, turnover treatments included replacing or returning the original male. Population experiments included pairs (MF), single-male groups (MFFF) and multi-male-multi-female (MMMFFF) groups. Females in the laboratory experiment and females in the field experiment with female groups differed in cohort (age and breeding experience combined, $O W$ - $n$ over-wintered nulliparous, $Y Y$ - $n$ year-born nulliparous, $Y Y$ - $p$ year-born parous). Significant effects are indicated in bold, tendencies in italics

Table 3 Post hoc tests within factor levels on the proportion of early to late births born in different male turnover treatments and population compositions in three field experiments on pregnancy termination in bank voles

\begin{tabular}{|c|c|c|c|c|c|}
\hline Within factor & Within-factor levels & Among factor levels & $\begin{array}{l}\text { No. of early } \\
\text { births }\end{array}$ & $\begin{array}{l}\text { No. of late } \\
\text { births }\end{array}$ & Fischer's exact $p$ \\
\hline \multirow[t]{6}{*}{ Male turnover treatment } & \multirow[t]{3}{*}{ Returned male } & MMMFFF & 5 & 2 & \multirow[t]{3}{*}{0.58} \\
\hline & & MFFF & 11 & 1 & \\
\hline & & MF & 8 & 2 & \\
\hline & \multirow[t]{3}{*}{ Replaced male } & MMMFFF & 7 & $\mathbf{0}$ & \multirow[t]{3}{*}{0.023} \\
\hline & & MFFF & 17 & 1 & \\
\hline & & MF & 6 & 5 & \\
\hline \multirow[t]{6}{*}{ Composition of population } & \multirow[t]{2}{*}{ MMMFFF } & Returned males & 5 & 2 & \multirow[t]{2}{*}{1.00} \\
\hline & & Replaced males & 7 & 0 & \\
\hline & \multirow[t]{2}{*}{ MFFF } & Returned male & 11 & 1 & \multirow[t]{2}{*}{0.46} \\
\hline & & Replaced male & 17 & 1 & \\
\hline & \multirow[t]{2}{*}{ MF } & Returned male & 8 & 2 & \multirow[t]{2}{*}{0.36} \\
\hline & & Replaced male & 6 & 5 & \\
\hline
\end{tabular}

After 1 week original males were removed, turnover treatments included replacing or returning the breeding male. Populations were either composed of multi-males-multi-females (MMMFFF), single-male-multi-females (MFFF), or an isolated male-female breeding pair (MF). Significant effects are indicated in bold 


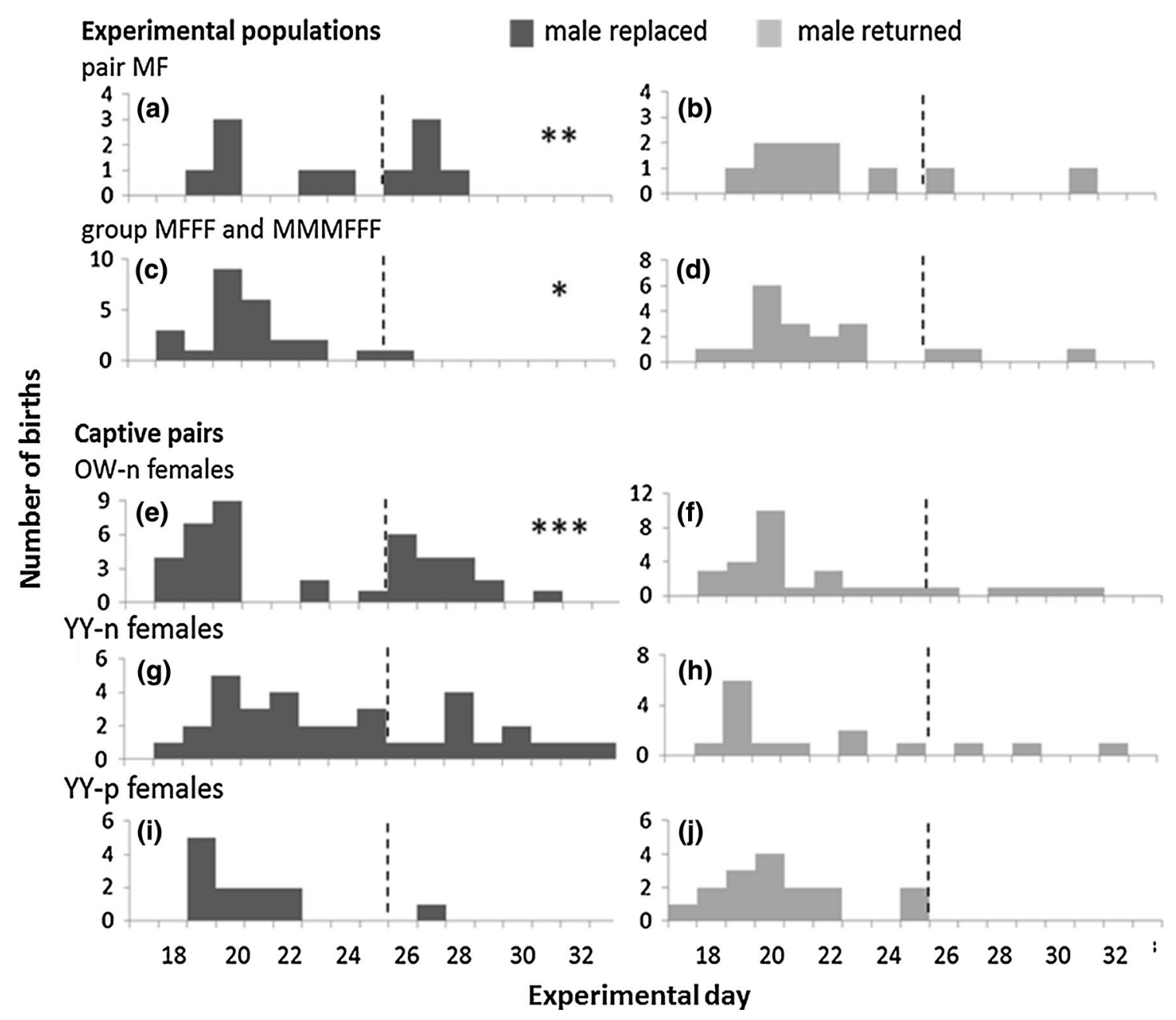

Fig. 3 Distribution of birth dates of bank vole litters after male turnover (black) or male return (control, grey). Experiments with different population compositions (a-d), and caged pairs $(\mathbf{e}-\mathbf{j})$ with different females' ages ( $O W$ overwintered, $Y Y$ yearborn) and female reproductive history ( $-n$ nulliparous, $-p$ parous). Hatched lines divide early (conceived before turnover date) and late births (conceived after

of 86 births $=35 \%)$ compared to if the male was returned $(8 / 60=13 \%$, Fig. 2$)$.

\section{H2: The Bruce effect as an alternative}

to paternity confusion (proportion of late births: MFFF > MMMFFF)

Between the multi-female group experiments, there was no effect of single male versus multiple males on the proportion of late births (4 late out of 44 total, 9\%, Figs. 2 and 3), and we found no interactive effect of male turnover and population composition (GLMM, number of males: $X^{2}=0.0, d f=1, p=0.92$; male turnover treatment; $X^{2}=0.0, d f=1, p=0.83$, female age: $X^{2}=0.1$, turnover date, possibly due to the Bruce effect). Stars indicated deviations from unimodal distributions (Hartigans' dip test (Hartigan and Hartigan 1985) with $* p<0.05, * * p<0.01$, *** $p<0.001$, with a and $\mathbf{e}$ indicating distributions with modes at both early and late birth intervals, while in c early birth was divided in two modes

$d f=1, p=0.74$; female breeding status: $X^{2}=0.3, d f=1$, $p=0.56$, Table 2).

H3: Absolute animal density affects the Bruce effect (proportion of late births; in large enclosures:

$M M M F F F>M F F F>M F)$ and $(M F$ small $>M F$ large $)$

Density did not affect the proportion of late births $\left(X^{2}=1.7\right.$, $d f=2, p=0.42, n=54$ females in large enclosures). Within the MF experiment we had used two enclosure sizes ( 5 births from small/5 from large in replace, $7 / 4$ in return treatment). Pregnancy rate was $75 \%$ in both enclosure sizes, and the proportion of late births was $42 \%$ in smaller enclosures and $22 \%$ in larger enclosures. An interaction of enclosure size 
and turnover treatment did not explain the probability of late births to occur (interaction: $X^{2}<0.4, p>0.50$ ).

\section{H4: Cohort effects on proportion of late births $($ OW-n $>$ YY-n > YY-p)}

In the pairing experiment on captive bank voles, the proportion of late births was affected by both male turnover treatment and female cohort (Fig. 2; Table 2). OW-n and YY-n females did not differ in the proportion of late births (32 and $\left.31 \%, X^{2}=0.0, d f=1, p=1.00\right)$, but YY-p females had a lower proportion of late births than the other cohorts $(4 \%$, $X^{2}=7.3, p=0.007$ and $X^{2}=6.4, p=0.012$ ). Although we could not detect a cohort-specific treatment effect in the statistical model (non-significant interaction effect), we found that the distribution of birth dates deviated from unimodality only for OW-n females in the replaced male treatment. $(D=0.11, p<0.001)$ with a distinct additional second peak from late births at day 26, and a first peak at day 19 (Fig. 3e) There was no indication of deviation from unimodality in this cohort in the male returned treatment, and in no other combinations of cohort and treatment (all $D<0.09$, all $p>0.25$, Fig. 3).

In the field experiments with groups of females (MMMFFF and MFFF), we had also used different cohorts of females. The proportion of late pregnancies in multi-female experiments was very small (9\%) and not depend on female age or cohorts (Table 2, please note that the small sample size did not allow testing effects of male number (H2) and female cohorts (H4) in the same model. We therefore ran separate models for the two hypotheses).

\section{Additional late pregnancies or replacement of early pregnancies?}

With an imbalanced distribution of the response variable (gravid or not) among population compositions and the occurrence of empty cells, it was impossible to run a binary model across all groups. Using post hoc tests within levels, we found no simple effects of population composition within turnover treatments on pregnancy rate, and we found no simple effects of turnover treatments within population compositions on pregnancy rates (all Fisher's exact tests, $p>0.49$ ).

In the multi-female experiments (MFFF vs MMMFFF), 44 litters were born to 54 recaptured females $(81 \%)$. Neither male numbers $\left(X^{2}=0.9, d f=1, p=0.40\right)$ nor male turnover $\left(X^{2}=0.2, d f=1, p=0.64\right)$ explained the rates of pregnancy in these experiments. Parous females had higher pregnancy rates (16/17) than nulliparous females $(28 / 37$, $\left.X^{2}=3.9, d f=1, p=0.048\right)$ and year-born females tended to have higher pregnancy rates $(28 / 33)$ than overwintered females $\left(15 / 20\right.$, one female with unknown age, $X^{2}=2.7$, $d f=1, p=0.099$, Table 4$)$.

In the pairing experiment on captive voles, the replacement of the original male did not add additional pregnancies $\left(X^{2}=2.1, d f=1, p=0.15\right)$. The probability of pregnancy differed among female age cohorts though $\left(X^{2}=14.9\right.$, $d f=2, p<0.001)$. Pregnancy rates were higher in both YY-n and YY-p (83 and $88 \%, X^{2}$ test: $\left.X^{2}=0.1, d f=1, p=0.80\right)$ as compared to OW-n females $\left(61 \%, X^{2}=7.7, p=0.006\right.$ and $\left.X^{2}=6.72, p=0.01\right)$. We found no interaction of cohort and male turnover treatment (Table 4).

Table 4 Pregnancy rates in multiple female groups of bank voles: results of generalised linear models (GLM) and mixed effect models (GLMM) with binomial error distribution and probit link function of the variables "probability of pregnancy"

\begin{tabular}{|c|c|c|c|c|c|}
\hline $\begin{array}{l}\text { Data base (sample size: pregnant/non pregnant, } \\
\text { model type) }\end{array}$ & Explanatory variable & Estimate & SE of estimate & $Z$ value & $p$ \\
\hline \multirow{6}{*}{$\begin{array}{l}\text { Field experiment with female groups }(n=44 / 10 \text {, } \\
\text { GLMM) }\end{array}$} & (Intercept) & 0.2 & 1.3 & 0.1 & 0.898 \\
\hline & Turnover & 0.4 & 0.1 & 0.3 & 0.772 \\
\hline & No. males & 1.0 & 0.1 & 0.7 & 0.480 \\
\hline & Interaction & 0.1 & 2.0 & 0.1 & 0.955 \\
\hline & Reproductive history (n:p) & 2.8 & 1.4 & 2.0 & 0.045 \\
\hline & Age (OW:YY) & 1.4 & 1.0 & 1.4 & 0.158 \\
\hline \multirow[t]{5}{*}{ Caged pairs $(n=146 / 62$, GLM) } & (Intercept) & 0.2 & 0.3 & 0.8 & 0.450 \\
\hline & Turnover & 0.5 & 0.3 & 1.5 & 0.148 \\
\hline & OW-n:YY-n & -1.1 & 0.4 & 2.7 & 0.006 \\
\hline & OW-n:YY-p & -1.6 & 0.6 & 2.8 & 0.006 \\
\hline & YY-n:YY-p & 0.5 & 0.7 & 0.8 & 0.437 \\
\hline
\end{tabular}

After 1 week original males were removed, turnover treatments included replacing or returning the breeding male. Population composition in the field experiments included single-male groups (MFFF) and multi-male-multi-female (MMMFFF) groups. Females in the laboratory experiment and females in the field experiment differed in age ( $O W$ overwintered, $Y Y$ yearborn) and reproductive history ( $n$ nulliparous, $p$ parous). Significant effects are indicated in bold 


\section{Discussion}

Breeding in MF pairs increased the proportion of late births after turnover of the male, compared to breeding in multifemale groups (supporting H1). Here we report first experimental evidence for pregnancy termination of female rodents in field populations after replacement of breeding male(s) by unfamiliar male(s). We conclude that pregnancy termination may be an adaptive behaviour to the specific, social condition of a single-female breeding with a single male, a condition which in small mammals in nature can occur only at low population densities in the increase phase of the annual population cycle. We suggest that the Bruce effect in a small mammal is not a laboratory artefact (as suggested by Wolff 2003), but represents a flexible adaptive response to male turnover in breeding pairs (Fig. 1).

Results from both captive pair and field experiments support the occurrence of late births after turnover; but we found no support for an increase of pregnancy rates. Although in the field experiment the overall statistical model of pregnancy rates indicated a tendency for an interaction of male turnover and population composition (Table 2), this interaction was not supported by simple effects post hoc tests. We, therefore, conclude that observed late births after male turnover were mainly a product of pregnancy termination rather than a significant proportion of additional pregnancies.

Breeding in single-female-single-male units at low population densities in the population increase phase may be a common feature of the social system of many rodent species with annual and multi-annual population density fluctuations. Some rodent species were observed to breed in isolated pairs at low densities but in large groups at high densities (mice: Schradin and Pillay 2005, voles: Lucia et al. 2008). Genetic monogamy was reported from low densities of voles, but genetic polyandry from high density (Streatfeild et al. 2011). Thus, depending on habitat saturation with breeding territories breeding systems of many rodent species are flexible.

For bank voles, a great variability in breeding systems has been reported so far. It includes female territoriality and breeding suppression above population density thresholds (Bujalska and Grüm 1989; Eccard and Ylönen 2001), loss of density dependence at very high densities (Eccard et al. 2011), high density group breeding (Ylönen et al. 1988) and small wintering aggregations of siblings (Ylönen and Viitala 1991). Social organisation at very low spring densities, and residence time of males at female nests has, to our knowledge, not been investigated in this species.

The adaptive value of pregnancy termination during a population bottleneck may also depend on the relatedness of the overwintered female to the breeding male. Bank voles overwinter in small aggregations of siblings and probably start breeding in spring with a locally available male sibling. An intruding unknown male may thus represent an adaptive opportunity for outbreeding. In mice, the chance for outbreeding increased the proportion of pregnancy blocks (Yamazaki et al. 1983, but see Rülicke et al. 2006). It remains to be tested experimentally whether this opportunity outweighs the costs for the female of delaying reproduction in cyclic populations.

Infanticide risk my males at low population density may differ from that at high population density. Paternity assurance for the breeding male is high in a pair-breeding condition. Consequently, after a turnover of the breeding male, a female's litter may be at greater infanticide risk (Ylönen and Horne 2002) than in high population density. Further, in rodents with altricial young, close guarding and attending of the female by the new male increases the risk of the litter being found by the intruder. Thus, behaviour of a male which breeds with a single female may pose a greater infanticide risk than behaviour of a male breeding with multiple females. The Bruce effect may therefore function as a counterstrategy to infanticide in single-male-single-female breeding situations.

We found no support for the Bruce effect acting as an alternative to paternity confusion (H2) to counteract infanticide in groups of females, independent of single or m multiple breeding males late births were rare. In many other mammals with a group structure of monopolisable females (a harem), females are threatened to lose their offspring through infanticide after turnover of the dominant male (Lukas and Huchard 2014). Different from the Bruce effect observed in one-male groups in primates (Hrdy 1979; Roberts et al. 2012) or horses (Berger 1983), female rodents in one male groups seem not to have to interrupt pregnancies after male turnover.

Possibly, the incidence of the Bruce effect is also affected by male mating behaviour. Male mate-guarding intensity and frequency of sexual harassment by the males (CluttonBrock and Parker 1995) is potentially lower for a female when alternative receptive females are available for the male (Parker 1974; Mathews 2002). Males with alternative breeding opportunities may be less insisting and can probably be avoided by the female, expelled from the territory, or aggressively evicted from the nest site (Koskela et al. 1997; Ylönen and Horne 2002), or the nest site can be hidden (Ebensperger 1998). According to socio-ecological theory, the distribution of risks and resources determines female distribution in space and time, whereas males adjust their spacing pattern to the distribution of receptive females (Clutton-Brock 1989; Altmann 1990). These patterns have been demonstrated experimentally, for example, for female grey mouse lemurs (Microcebus murinus: Dammhahn and Kappeler 2009) and male and female grey-sided voles (Clethrionomys rufocanus: Ims 1988). 
The proportion of late births did not increase with absolute density (refuting H3). We found delayed births both in the highest densities (pairs in small cages) and the lowest densities (pairs in large enclosures), while a doubling or tripling of density in the large enclosures did not increase the incidence of pregnancy termination. Further, a 10-fold increase between larger and smaller enclosures within the MF experiment did not conclusively affect the occurrence of late births, although other processes like spacing behaviour, breeding suppression, and physiology can be affected by density (e.g., Eccard et al. 2011). These results suggest that female reproductive strategies are based rather on social cues like population structure or male sexual behaviour specific to pair breeding, than on density cues alone.

In house mice kept in groups (on very limited space), the incidence of pregnancy termination was not augmented by the number of males but reduced by the number of females (Bruce 1963), supporting our H1 and H3. Bruce discussed hormonal mechanisms and maladaptive effects of crowding, but her findings can also be interpreted as an adaptive flexibility of female reproductive behaviour to population composition and behaviour of the male, rather than being directly density related.

We found female cohort effects on the timing of births (supporting $\mathrm{H} 4$ ) in the breeding experiment on captive voles. Overwintered females without breeding experience (OW-n) had higher proportions of late births (Figs. 2, 3) than experienced young-of-the-year breeders. Female cohorts also differed in pregnancy rates, with YY females having higher pregnancy rates than OW females, and parous females having higher pregnancy rates than nulliparous females (Fig. 2). Overall, these results confirm earlier findings: in many rodent species, females breeding for the first time were more likely to interrupt their pregnancy than parous females after male turnover (Stehn and Jannett 1981; Clulow et al. 1982, but see Chipman and Fox 1966). Moreover, younger females are more likely to interrupt a pregnancy than older females (Clulow and Langford 1971; Heske 1987). In annually fluctuating rodent populations overwintered and first time breeding females are the prevailing cohort during the lowest annual population density in the population increase phase in spring (Fig. 1). Observations of ovulation scars in female voles captured in spring (Mallory and Clulow 1977) may further support our hypothesis that pregnancy termination may be of seasonal importance and restricted to specific reproductive strategies of low density spring populations, consisting of mainly $\mathrm{OW}-\mathrm{n}$ females (Fig. 1). With age structure closely related to annual density cycles, our results suggest that females might adjust their counterstrategies flexibly infanticide risk by males, which varies according to the prevailing social environmental conditions (Fig. 1).

\section{Conclusions}

Here, we provide first indication for delayed breeding after male turnover in experimental field populations of rodents, suggesting that the Bruce effect is not a laboratory artefact. The adaptive value of costly female counterstrategies in sexual conflicts probably depends on the social environment of the breeding female, and thus varies with population density and season. The Bruce effect in rodents may be an adaptation in fluctuating populations to breeding in single-female-single-male breeding units at low densities in the increase phase of the annual population cycle, and to associated increased risks of inbreeding or infanticide. With spring litters having a high reproductive value in increasing seasonal populations, pregnancy termination to prevent infanticide or reduce inbreeding may be highly adaptive for a rodent female at low densities in the increase phase, even at the costs of delaying reproduction.

Acknowledgements We thank Konnevesi Research Station for material support of voles and researchers. Ines Klemme and Chris Madden are thanked for help with trapping and vole maintenance in the Finish part of the study, Angela Puschmann und Julia Scholl in the German Part. JAE and HY were supported by the Finish Academy of Science (Suomen Akatemia) and JAE by the German Science Foundation (DFG, EC361/11-1). Three anonymous colleagues in the Peerage of Science community, and colleagues met at the ISBE in Exeter 2016 are thanked for their critical reviews of earlier versions of the manuscript.

Author contribution JAE conceived and designed the field and laboratory experiment in Finland, which were performed together with HY. JAE and MD conceived and designed the field experiment in Germany, that was performed by JAE and helpers. JAE analysed the data and wrote the first draft of the manuscript which was refined and edited and improved by MD and HY.

\section{Compliance with ethical standards}

Data were gathered as part of standard breeding routines of bank voles at Konnevesi Research Station, breeding and field experiments were conducted according to Finnish legislation on animal research, with institutional guidelines approved by the University of Jyväskylä Board for Animal Experiments. Vole capture in Germany were permitted by the Landesumweltamt Brandenburg (reference number RW-7.1 24.01.01.10), keeping and breeding of voles in laboratory and enclosure was permitted by the Landesamt für Umwelt, Gesundheit und Verbraucherschutz Brandenburg. This article does not contain studies with human participants.

Open Access This article is distributed under the terms of the Creative Commons Attribution 4.0 International License (http://creativecommons.org/licenses/by/4.0/), which permits unrestricted use, distribution, and reproduction in any medium, provided you give appropriate credit to the original author(s) and the source, provide a link to the Creative Commons license, and indicate if changes were made. 


\section{References}

Altmann J (1990) Primate males go where the females are. Anim Behav 39:193-195

Andreassen HP, Gundersen G (2006) Male turnover reduces population growth: an enclosure experiment on voles. Ecology 87:88-94

Bates D, Maechler M, Bolker B, Walker S (2014) lme4: linear mixedeffects models using Eigen and S4. R package version 1.1-6. doi:10.18637/jss.v067.i01

Berger J (1983) Induced abortion and social factors in wild horses. Nature 303:59-61

Bruce HM (1959) Exteroceptive block to pregnancy in the mouse. Nature 184:105

Bruce HM (1960) A block to pregnancy in the mouse caused by proximity of strange males. J Reprod Fertil 1:96-103

Bruce HM (1963) Olfactory block to pregnancy among grouped mice. J Reprod Fertil 6:451-460

Bujalska G (1983) Ecology of the bank vole: reproduction. Acta Theriol 28:148-161

Bujalska G, Grüm L (1989) Social organisation of the bank vole (Clethrionomys glareolus, Schreber 1780) and its demographic consequences: a model. Oecologia 80:70-81

Chipman RK, Fox KA (1966) Factors in pregnancy blocking: age and reproductive background of females: numbers of strange males. J Reprod Fertil 12:399-408

Clulow FV, Langford PE (1971) Pregnancy-block in the meadow vole, Microtus pennsylvanicus. J Reprod Fertil 24:275-277

Clulow FV, Franchetto EA, Langford PE (1982) Pregnancy failure in the red-backed vole, Clethrionomys gapperi. J Mammal 63:499-500

Clutton-Brock TH (1989) Mammalian mating systems. P Roy Soc Lond B Bio 236:339-372

Clutton-Brock TH, Parker GA (1995) Sexual coercion in animal societies. Anim Behav 49:1345-1365

Crespin L, Verhagen R, Stenseth NC, Yoccoz NG, Prevot-Julliard AC, Lebreton JD (2002) Survival in fluctuating bank vole populations: seasonal and yearly variations. Oikos 98:467-479

Dammhahn M, Kappeler PM (2009) Females go where the food is: does the socio-ecological model explain variation in the social organisation of solitary foragers? Behav Ecol Sociobiol 63:939-952

De la Maza H, Wolff JO, Lindesey A (1999) Exposure to strange adults does not cause pregnancy disruption or infanticide in the graytailed vole. Behav Ecol Sociobiol 45:107-113

Ebensperger LA (1998) Strategies and counterstrategies to infanticide in mammals. Biol Rev 73:321-346

Ebensperger L, Blumstein D (2007) Nonparental Infanticide. In: Wolff J, Sherman P (eds) Rodent societies. An ecological and evolutionary perspective. University of Chicago Press, Chicago, pp 267-279

Eccard JA, Herde A (2013) Seasonal variation in the behaviour of a short-lived rodent. BMC Ecol 13:43

Eccard JA, Wolf JBW (2009) Effects of brood size on multiple-paternity rates: a case for 'paternity share' as an offspring-based estimate. Anim Behav 78:563-571

Eccard JA, Ylönen H (2001) Initiation of breeding after winter in bank voles: effects of food and population density. Can J Zool 79:1743-1753

Eccard JA, Jokinen I, Ylonen H (2011) Loss of density-dependence and incomplete control by dominant breeders in a territorial species with density outbreaks. BMC Ecol 11:8

Fox J (2005) The R commander: a basic statistics graphical user interface to R. J Stat Softw 14:1-42

Fox J, Weisberg S (2011) An R companion to applied regression. SAGE, Thousand Oaks
Hackländer K, Arnold W (1999) Male-caused failure of female reproduction and its adaptive value in alpine marmots (Marmota marmota). Behav Ecol Sociobiol 5:592-597

Hartigan JA, Hartigan PM (1985) The dip test of unimodality. Ann Stat 13:70-84

Heske EJ (1987) Pregnancy interruption by strange males in the California vole. J Mammal 68:406-410

Heske EJ, Nelson RJ (1984) Pregnancy interruption in Microtus ochrogaster: laboratory artifact or field phenomenon? Biol Reprod 31:97-103

Hrdy SB (1979) Infanticide among animals—review, classification, and examination of the implications for the reproductive strategies of females. Ethol Sociobiol 1:13-40

Ims RA (1988) Spatial clumping of sexually receptive females induce space sharing among male voles. Nature 335:541-543

Klemme I, Eccard JA, Ylönen H (2007) Why do female bank voles, Clethrionomys glareolus, mate multiply? Anim Behav 73:623-628

Klemme I, Ylönen H, Eccard JA (2008) Long term fitness benefits of polyandry in a small mammal, the bank vole Clethrionomys glareolus. Proc R Soc Lond B 275:1095-1100

Koskela E, Mappes T, Ylonen H (1997) Territorial behaviour and reproductive success of bank vole Clethrionomys glareolus females. J Anim Ecol 66:341-349

Lucia KE, Keane B, Hayes LD, Lin YK, Schaefer RL, Solomon NG (2008) Philopatry in prairie voles: an evaluation of the habitat saturation hypothesis. Behav Ecol 19:774-783

Lukas D, Huchard E (2014) The evolution of infanticide by males in mammalian societies. Science 346:841-844

Maechler M (2013) diptest: Hartigan's Dip Test Statistic for Unimodality. R package, Version $0.75-7$

Mahady SJ, Wolff JO (2002) A field test of the Bruce effect in the monogamous prairie vole (Microtus ochrogaster). Behav Ecol Sociobiol 52:31-37

Mallory FF, Clulow FV (1977) Evidence of pregnancy failure in the wild meadow vole, Microtus pennsylvanicus. Can J Zool 55:42736

Marashi Rülicke T (2012) The Bruce effect in Norway rats. Biol Reprod 86:1-5

Mathews LM (2002) Tests of the mate-guarding hypothesis for social monogamy: does population density, sex ratio, or female synchrony affect behavior of male snapping shrimp (Alpheus angulatus)? Behav Ecol Sociobiol 51:426-432

Milligan SR (1976) Pregnancy blocking in the vole, Microtus agrestis. I Effect of the social environment. J Reprod Fertil 46:91-95

Opperbeck A, Ylönen H, Klemme I (2012) Infanticide and population growth in the bank vole (Myodes glareolus): the effect of male turnover and density. Ethology 118:178-186

Parker GA (1974) Courtship persistence and female-guarding as male time-investment strategies. Behav 48:157-184

Parker GA (1979) Sexual selection and sexual conflict. In: Blum MS, Blum NA (eds) Sexual selection and reproductive competition in insects. Academic, London, pp 123-166

Parker GA (2006) Sexual conflict over mating and fertilization: an overview. Philos Trans R Soc Lond B 361:235-259

Parkes AS, Bruce HM (1961) Olfactory stimuli in mammalian reproduction-odour excites neurohumoral response affecting estrus, pseudopregnancy and pregnancy in mouse. Science 134:1049-1053

Pillay N, Kinahan A (2009) Mating strategy predicts the occurrence of the Bruce effect in the vlei rat Otomys irroratus. Behav 146:139-151

Prevot-Julliard AC, Henttonen H, Yoccoz NG, Stenseth NC (1999) Delayed maturation in female bank voles: optimal decision or social constraint? J Anim Ecol 68:684-697

R-Development-Core-Team (2013) A language and environment for statistical computing. R Foundation for Statistical Computing, Vienna, Austria. ISBN 3-900051-07-0 
Roberts EK, Lu A, Bergman TJ, Beehner JC (2012) A Bruce effect in wild Geladas. Science 335:1222-1225

RStudio Team (2015) RStudio: integrated development for R. RStudio Inc, Boston

Rülicke T, Guncz N, Wedekind C (2006) Early maternal investment in mice: no evidence for compatible-genes sexual selection despite hybrid vigor. J Evol Biol 19:922-928

Schradin C, Pillay N (2005) Intraspecific variation in the spatial and social organization of the African striped mouse. J Mammal 86:99-107

Schwagmeyer RL (1979) The Bruce effect: an evaluation of male/ female advantages. Am Nat 114:932-938

Stehn RA, Jannett FJ (1981) Male induced abortions in various microtine rodents. J Mammal 62:369-372

Streatfeild CA, Mabry KE, Keane B, Crist TO, Solomon NG (2011) Intraspecific variability in the social and genetic mating systems of prairie voles, Microtus ochrogaster. Anim Behav 82:1387-1398

Westlin LF (1981) Sterile matings at the beginning of the breeding season in Clethrionomys rufocanus and Microtus agrestis. Can J Zool 60:2568-2571
Wolff JO (2003) Laboratory studies with rodents: facts or artifacts? Bioscience 53:421-427

Yamazaki K, Beauchamp GK, Wysocki CJ, Bard J, Thomas L, Boyse EA (1983) Recognition of H-2 types in relation to the blocking of pregnancy in mice. Science 221:186-188

Ylönen H, Horne TJ (2002) Infanticide and effectiveness of pup protection in bank voles: does the mother recognise a killer? Acta Ethol 4:97-101

Ylönen H, Viitala J (1991) Social overwintering and food distribution in the bank vole. Holarctic Ecol 14:131-137

Ylönen H, Kojola T, Viitala J (1988) Changing female spacing behavior and demography in an enclosed breeding population of Clethrionomys glareolus. Holarctic Ecol 11:286-292

Yoccoz NG, Stenseth NC, Henttonen H, Prevot-Julliard AC (2001) Effects of food addition on the seasonal density-dependent structure of bank vole Clethrionomys glareolus populations. J Anim Ecol 70:713-720

Zuur AF, Ieno EN, Walker NJ, Saveliew AA, Smith GM (2009) Mixed effect models and extensions in Ecology with R. Springer, New York 